\title{
Anti-asthmatic effect of Ping-Chuan Formula in asthmatic mice, and its molecular mechanism of action
}

\author{
Xi Ming ${ }^{1,2}$, Wanchao Xu ${ }^{1,2}$, Yazun Liu ${ }^{1,2}$, Xinguang Zhang ${ }^{1}$, Li Bai ${ }^{1}$, Zheng Xue ${ }^{1 *}$, \\ Jianer $\mathbf{Y u}^{1}$ \\ ${ }^{1}$ Shanghai Municipal Hospital of Traditional Chinese Medicine, Shanghai University of Traditional Chinese Medicine, Shanghai \\ 200071, 2Shanghai University of Traditional Chinese Medicine, Shanghai 201203, PR China
}

*For correspondence: Email: lyz1041857257@126.com; Tel: +86-021-56639828-2303

\begin{abstract}
Purpose: To investigate the anti-asthmatic effect of Ping-Chuan Formula (PCF) in a mouse model, and the associated molecular mechanisms.

Methods: Asthma mice were induced using ovalbumin (OVA), and PCF (600 mg/kg) was administered to the mice for 4 weeks. Sections of lung tissues were examined microscopically. The expressions of interleukins (ILs), interferon (IFN)- $\gamma$, transforming growth factor (TGF) $\beta$ were assayed, while lung tissue expressions of Toll like receptor (TLR)-4, GATA binding protein (GATA)-3, Ox40 ligand (OX4OL), indoleamine 2,3-dioxygenase (IDO), and forkhead box P3 (Foxp3) determined. The $T$ box expressed in $T$ cells (T-bet) was evaluated using western blotting. The expressions of MHC II and co-stimulators (CD 11c, $C D 80$ and $C D$ 86) of dendritic cells (DCs) were determined by flow cytometry.

Results: PCF decreased inflammation in lung, and also down-regulated IL-4, -6, -17 and TGF- $\beta$ ( $p<$ $0.01)$, whereas IL-10 and IFN- $y$ expressions were up-regulated $(p<0.01)$. Moreover, PCF decreased the expressions of TLR-4, GATA-3 and OX40L in lung tissue, and promoted Foxp3, IDO and T-bet. Besides, PCF decreased the levels of MHC II and co-stimulators (CD 80 and CD 86) on the surface of DCs.

Conclusion: PCF exerts anti-asthmatic effect in mice via inhibition of inflammation, and modulation of MHC II and co-stimulators on the surface of DCs. These findings suggest that PCF is a promising candidate drug for treating asthma in humans.
\end{abstract}

Keywords: Ping-Chuan Formula, Asthma, Inflammatory reactions, Dendritic cells

\begin{abstract}
This is an Open Access article that uses a funding model which does not charge readers or their institutions for access and distributed under the terms of the Creative Commons Attribution License (http://creativecommons.org/licenses/by/4.0) and the Budapest Open Access Initiative (http://www.budapestopenaccessinitiative.org/read), which permit unrestricted use, distribution, and
\end{abstract} reproduction in any medium, provided the original work is properly credited.

Tropical Journal of Pharmaceutical Research is indexed by Science Citation Index (SciSearch), Scopus, International Pharmaceutical Abstract, Chemical Abstracts, Embase, Index Copernicus, EBSCO, African Index Medicus, JournalSeek, Journal Citation Reports/Science Edition, Directory of Open Access Journals (DOAJ), African Journal Online, Bioline International, Open-J-Gate and Pharmacy Abstracts

\section{INTRODUCTION}

Asthma, an intractable airway inflammatory disease which seriously affects the quality of life of lots of children and adults, is featured by excessive production of mucus in the lung airway $[1,2]$. Studies have shown that over 300 million patients in the world suffer from asthma [3,4]. The currently used conventional drugs only temporarily alleviate the asthma symptoms, implying that radical cure of asthma is not yet feasible. Moreover, these drugs above often results in several adverse effects $[\underline{3}, 4]$. Thus, 
there is need for development of more alternative therapies for asthma.

Natural herbal medicines have been effectively applied for the treatment of various diseases. These herbs have low toxicity, and they are reliable. Traditional Chinese medicines (TCMs) are also recognized as promising resources used for discovery of candidate drugs for the treatment of immunological diseases $[3,5]$. Ping-ChuanFormula (PCF) was developed by Professor Jianer $\mathrm{Yu}$ based on his clinical experience from long-term treatment of asthma patients at the Shanghai Municipal Hospital of Traditional Chinese Medicine (SMHTCM). It is composed of the Ephedra sinica Stapf, Peach kernel, Semen armeniacae Amarae, Fructus perillae, Rainworm and Semen raphani.

In an earlier study, ten major components of PCF were identified using HPLC assay. These components were baicalin, wogonin, tabersonine, tanshinone IIA, etc [6]. Studies have demonstrated that PCF is effective in the treatment of asthma, although the associated molecular mechanisms are still not clear $[\underline{7}, \underline{8}]$. In this investigation, the anti-asthma effect of PCF on ovalbumin (OVA) stimulated asthma mice, and the likely mechanisms involved, were investigated.

\section{EXPERIMENTAL}

\section{Plant medicines and preparation of PCF}

All plant medicines were acquired from the Shanghai TCMs company, and the water extracts of PCF was prepared by the pharmacy department of SMHTCM.

\section{Ethical approval}

This research was carried out in line with the international animal study guidelines [9], and the study protocol received approval from the Animal Ethics Committee of SMHTCM (no. 20180711am-01).

\section{Animal experimental protocols}

Fifty-two mice (ranging from $18 \mathrm{~g}$ to $22 \mathrm{~g}$ ) were bought from the Shanghai Animal Center. There are four groups designed in the experiments, with 13 mice per group: normal group, model group, positive drug (dexamethasone, Dex) treatment group, and PCF treatment groups (600 $\mathrm{mg} / \mathrm{kg} /$ day). Mice were immunized with OVA (50mg, Sigma-Aldrich, USA) and aluminum hydroxide (2mg) on days 1 and 14 (i.p.). Subsequently, using the ultrasonic nebulizer, from day 21 to day 28 , the mice were treated with $5 \%$ OVA solution for a $40 \mathrm{~min}$. Dex and PCF were administered orally from day 28 to day 56 at doses of 1.5 and $600 \mathrm{mg} / \mathrm{kg} /$ day. Then, 24 $\mathrm{h}$ after the treatment, 10 mice from each group were killed by breaking the neck, and bronchoalveolar lavage fluids (BALFs) and lung samples were sampled and kept at $-60{ }^{\circ} \mathrm{C}$. In addition, the remaining 3 mice in each group were used for preparation of dendritic cells (DCs).

\section{Histochemical assays}

Paraformaldehyde (10\%) fixation was performed for the lung tissue for 1 day, then the tissue was carried out with paraffin embedding, and subsequently sliced into 5- $\mu \mathrm{m}$. Thereafter, hematoxylin \& eosin staining was carried out and finally pathological changes were analyzed using an optical microscope, and photographed.

\section{Enzyme-linked immunosorbent assay (ELISA)}

Levels of IL-4, IL-6, IL-10, IL-17, IFN-y and TGF$\beta$ in BALFs were quantified using their respective commercial ELISA kits (Bioswamp Co., Shanghai, China) in line with the manufacturer's instructions.

\section{Western blotting determination}

Total proteins of the lung tissues were prepared by homogenizing in lysis buffer. Then, 35- $\mu \mathrm{g}$ samples of total proteins were separated using sodium dodecyl sulfate-polyacrylamide gel electrophoresis, and transferred to PVDF membrane. Thereafter, the PVDF membrane was probed overnight at $4^{\circ} \mathrm{C}$ with primary antibodies for toll like receptor (TLR)-4, indoleamine 2,3-dioxygenase (IDO) and Ox40 ligand (OX40L) (Santa Cruz Biotech, Delaware Ave Santa Cruz, USA), GATA-3, Foxp3, T-bet and GAPDH (Abcam Co., Cambridge, UK). Then, the PVDF membrane was incubated with secondary antibodies for $1 \mathrm{~h}$ at $25^{\circ} \mathrm{C}$. Lastly, the target bands were visualized through chemiluminescence, with GAPDH as the internal reference.

\section{Preparation of DCs and cell culture}

Bone-marrow-derived dendritic cells (DCs) were prepared from the femur and tibia of BALB/c mice bone marrow according to a previously reported procedure [10]. Suspensions of bone marrow cells (BMCs) were centrifuged, and the BMCs were cultured in RPMI-1640 medium containing $10 \%$ FBS. Thereafter, the cells were plated in culture flask at $37^{\circ} \mathrm{C}\left(3 \times 10^{5}\right.$ cells $\left./ \mathrm{mL}\right)$ 
(5 \% CO 2 ). In addition, GM-CSF (20 ng/mL) and IL-4 (10 ng/mL) were supplemented to each culture flask on the $1^{\text {st }}, 3^{\text {rd }}$ and $6^{\text {th }}$ days of culture. The DCs were harvested on the $9^{\text {th }}$ day of culture.

\section{Flow cytometry}

The DCs were harvested and stained with antiMHCII FITC, anti- CD11C FITC (eBioscience Co., Kunshan, China), anti- CD80 FITC and antiCD86 FITC (BD Pharmingen, Franklin Lakes, NJ, USA). Subsequently, the DCs were analyzed using flow cytometry (BD Bioscience, USA).

\section{Real-time PCR}

Total RNA was prepared from the harvested DCs through Trizol reagent. The total RNA was reverse-transcribed to cDNA and subjected to reverse transcription using quantitative real-time PCR machine (ABI-7300, USA). The sequences of the mRNA primers used for the real-time PCR are indicated on Table 1. Reverse transcription was done following the manufacturer's introduction.

\section{Statistical processing}

Results are exhibited as mean \pm standard deviations. Statistical differences were done by one-way analysis of variance and Dunnet- $t$ multiple comparison analysis; $p<0.05$ were taken as indicative of statistical significance.

\section{RESULTS}

\section{PCF ameliorated inflammatory reaction in lung tissues}

The results shown in Figure 1 indicated that in the normal group, the integrity of the bronchial wall tissues appeared normal and intact, and no obvious pathological changes were seen. However, in the model group, the bronchial walls were thickened and injured. In particular, the airway lumens were narrowed, with inflammatory cell infiltration in the airway wall. Interestingly, in the positive drug and PCF groups, the OVAinduced pathological changes were markedly ameliorated.

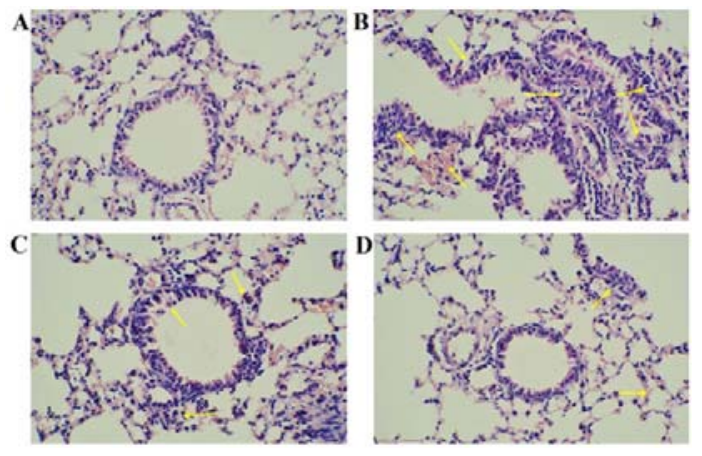

Figure 1: Histochemical features of lung tissues (magnification: $\times 200$ ). A - D represent normal, model, positive and PCF groups. All drugs were administered orally

\section{PCF regulated cytokines expressions in asthmatic mice}

As shown in Figure 2, the results demonstrated significant increases of IL-4, IL-6, IL-17 and TGF$\beta(p<0.01)$ in BALFs of model group, whereas IFN-y and IL-10 levels were significantly decreased in BALFs of model mice $(p<0.01)$. Interestingly, treatment with PCF for 28 days resulted in marked down- regulations of IL-4, IL$6, \mathrm{IL}-17$ and TGF- $\beta$ ( $p<0.01)$, whereas IL-10 and IFN- $Y$ were up-regulated $(p<0.01$, vs. model mice).

PCF regulated TRL-4, GATA-3, OX40L, IDO, Foxp3 and T-bet in asthmatic mice

As shown in Figure 3, compared with normal mice, OVA stimulation increased the levels of TLR-4, GATA-3 and OX40L in lung tissues, whereas reduced the IDO, Foxp3 and T-bet. Interestingly, compared with model mice, PCF decreased the OVA-induced up-regulations in expressions of TLR-4, GATA-3 and OX40L in lung tissues, and increased the expressions of IDO, Foxp3 and T-bet.

Table 1: Primers used for the Real time PCR

\begin{tabular}{llll}
\hline Gene name & & Primer sequence & Size \\
\hline \multirow{2}{*}{ IDO } & $\mathrm{F}$ & 5' AAGGGCTTCTTCCTCGTCTC 3' & $184 \mathrm{bp}$ \\
& $\mathrm{R}$ & 5' CCACAAAGTCACGCATCCTC 3' & \\
OX40L & $\mathrm{F}$ & 5' ACCCTCCAATCCAAAGAC 3' & $127 \mathrm{bp}$ \\
& $\mathrm{R}$ & 5' TCGCACTTGATGACAACC 3' & \\
GAPDH & $\mathrm{F}$ & 5' ATCACTGCCACCCAGAAG 3' & \\
& $\mathrm{R}$ & 5' TCCACGACGGACACATTG 3' & \\
\hline
\end{tabular}

F: Forward primer, R: Reverse primer 

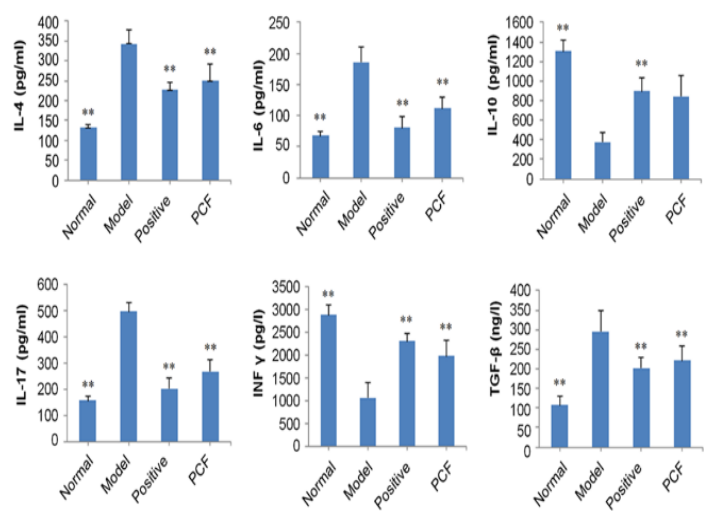

Figure 2: Effect of PCF on cytokine expressions in BALFs. All drugs were administered orally. Data are expressed as mean \pm SD $(\mathrm{n}=10),{ }^{* *} p<0.01$, compared to the model
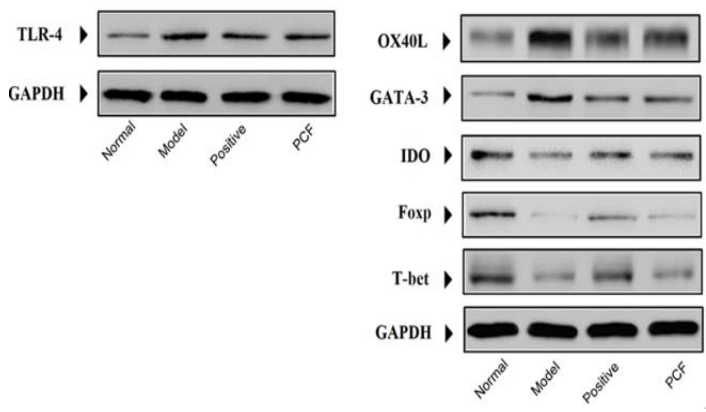

Figure 3: Effect of PCF on the expressions of TRL-4, GATA-3, OX40L, IDO, Foxp3 and T-bet in lung tissues of OVA-challenged mice. The protein expressions were determined using western blot assays. All drugs were administered orally

\section{PCF regulated immunological functions in DCs of asthmatic mice}

The levels of CD11c, CD80, CD86 and MHC-II of DCs in OVA-challenged mice were determined. As shown in Figure 4-7, apart from CD11C (Figure 4), the expressions of CD80 (Figure 5), CD86 (Figure 6), MHC-II (Figure 7) of DCs were up-regulated after OVA stimulation. However, PCF could markedly down-regulate the expressions of CD80, CD86 and MHC-II.

PCF regulated TRL-4, GATA-3, OX40L, IDO, Foxp3 and T-bet of asthmatic mice

The results in Figure 8 show that after stimulation with OVA, the expressions of OX40L in DCs were up-regulated, whereas the mRNA and protein expressions of IDO were down-regulated. However, compared with model mice, PCF treatment decreased the expressions of OX40L in DCs, and increased the mRNA and protein expressions of IDO.
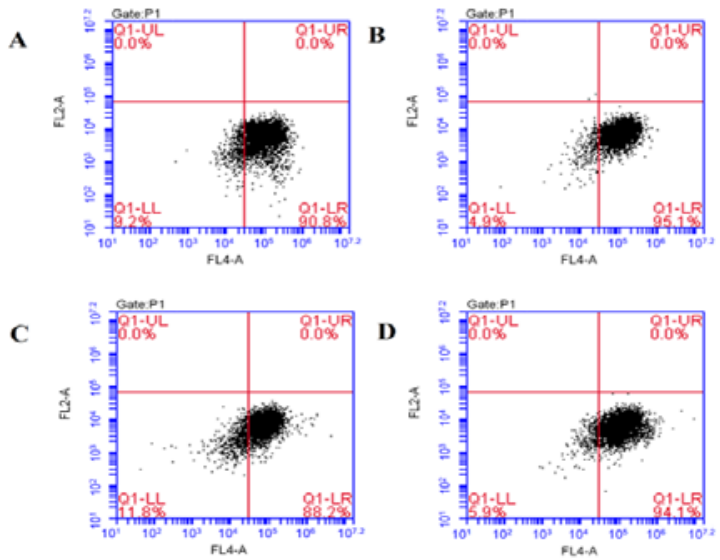

Figure 4: Effect of PCF on the expressions of CD11c on the surface of DCs in OVA-challenged mice, as measured using flow cytometry. A-D represented the Normal, Model, Positive and PCF treatment groups
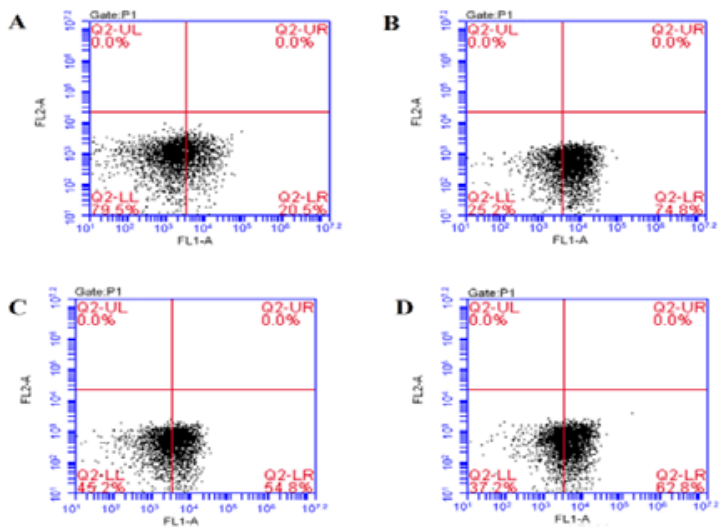

Figure 5: Effect of PCF on the expressions of CD80 on the surface of DCs in OVA-challenged mice, as measured using flow cytometry. A-D represented the Normal, Model, Positive and PCF treatment groups
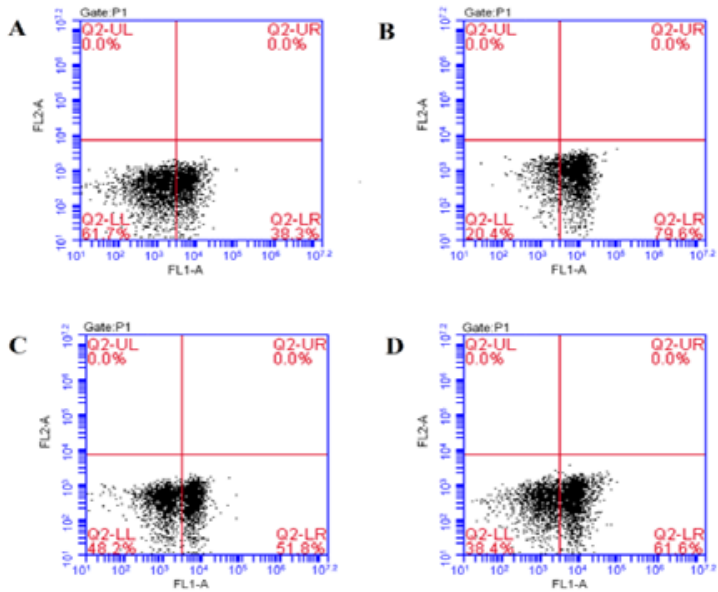

Figure 6: Effect of PCF on the expressions of CD86 on the surface of DCs in OVA-challenged mice, as measured using flow cytometry. A-D represented the Normal, Model, Positive and PCF treatment groups 


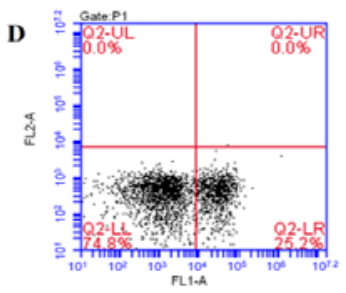

B
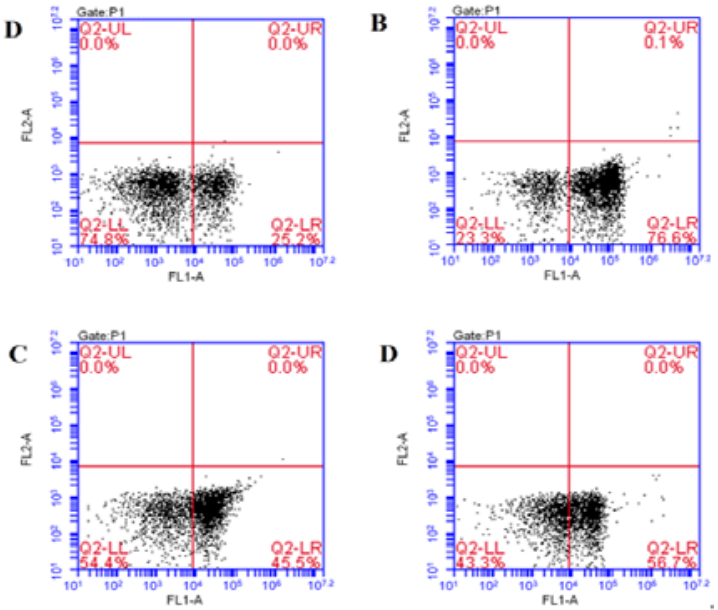

Figure 7: Effect of PCF on the expressions of MHC-II on the surface of DCs in OVA-challenged mice, as measured using flow cytometry. A-D represented the Normal, Model, Positive and PCF treatment groups

A

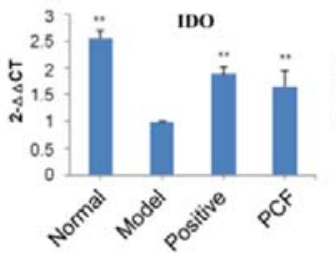

B

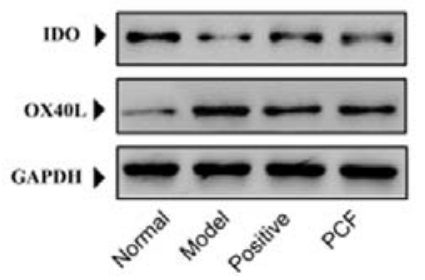

Figure 8: Effect of PCF on the mRNA $(A)$ and protein (B) expressions of OX40L and IDO in DCs of OVAchallenged mice. ${ }^{\star *} p<0.01$, compared to the model

\section{DISCUSSION}

Animal experiments are essential in the study of the pathologies of diseases to enhance the discovery of effective candidate drugs for treating diseases [11]. The OVA-induced asthma is a widely used experimental animal model for investigating the pathological mechanisms of asthma, and for screening candidate drugs for asthma [3, 12]. In the present research, OVAinduced allergic asthma in mouse was successfully prepared. It is known that airway inflammation exhibits key roles in pathogenesis of asthma.

Previous investigations revealed that asthma symptoms can be effectively alleviated or controlled through inhibition of airway inflammatory reactions $[13, \underline{14}$. The results of histopathological examination revealed PCF suppressed inflammatory reactions in lung tissues of OVA-induced asthma mice. In addition, PCF reduced inflammatory cytokines in BALFs, whereas it increased the levels of antiinflammatory cytokines i.e., IFN- $\mathrm{Y}$ and IL-10. Clinical researchers have reported high levels of IL-17 and TGF- $\beta$ in serum/BALFs of asthma patients $[15,16]$. It is known that IL-17, an early inflammatory cytokine, activates TGF- $\beta$, resulting in airway inflammation, and even airway remodeling [15-17]. In the present study, PCF decreased IL-7 and TGF- $\beta$ in BALFs of OVAinduced asthma mice. Thus, PCF exerts inhibitory potential on inflammatory reactions in lung tissues of asthma patients.

Studies have revealed that toll like receptor (TLR) 4 plays important role in inflammatory reactions $[18,19]$. The relative amounts of GATA3 , OX40L and T-bet influence the balance in Th1/Th2 cytokine ratio. Indeed, GATA-3 and OX40L activate the production of Th2 cytokines, and T-bet usually triggers the production of Th1 cytokines $[\underline{20}, \underline{21}]$. Increased GATA-3 could moderate the Th1/Th2 $[20,21]$. In addition, it has been reported that increase of IDO and Foxp3 could alleviate asthma patients' symptoms $[22, \underline{23}]$.

In the present study, MXDT moderated balance in Th1/Th2 cytokine ratio via regulation of TRL-4, GATA-3, OX40L, IDO and Foxp3, as well as Tbet. Dendritic cells (DCs) are important in innate and acquired immune responses to allergens. They initiate a complex process characterized by increased levels of $\mathrm{MHC} \mathrm{II}$ and co-stimulators such as CD11c, CD40, CD80 and CD86, resulting in imbalance in Th1/Th2 cytokine ratio and enhancement of asthma $[14,24,25]$. Previous investigations have revealed that decreases in the levels of MHC II and co-stimulators on the surface of DCs could be beneficial for decreasing pro-inflammatory cytokines and alleviating asthma symptoms [14,24,25]. The findings showed PCF effectively reduced MHC II, CD80 and CD86 in DCs.

\section{CONCLUSION}

The findings of this study indicate that PCF exerts anti-asthmatic effects in OVA-induced asthma mice, most likely through molecular mechanisms involving inhibition of inflammatory reactions, and modulation of the expressions of MHC II and co-stimulators on the surface of DCs. Thus, the findings suggest that PCF is a promising candidate drug for the management of asthma.

Trop J Pharm Res, November 2021; 20(11): 2329 


\section{DECLARATIONS}

\section{Acknowledgement}

This work was supported by the National Natural Science Foundation of China (no. 81874488).

\section{Conflict of interest}

No conflict of interest is associated with this work.

\section{Contribution of authors}

We declare that this work was done by the authors named in this article and all liabilities pertaining to claims relating to the content of this article will be borne by the authors. Jianer $\mathrm{Yu}$ and Zheng Xue contributed equally to this manuscript.

\section{Open Access}

This is an Open Access article that uses a funding model which does not charge readers or their institutions for access and distributed under the terms of the Creative Commons Attribution License (http://creativecommons.org/licenses/by/ 4.0) and the Budapest Open Access Initiative (http://www.budapestopenaccessinitiative.org/rea d), which permit unrestricted use, distribution, and reproduction in any medium, provided the original work is properly credited.

\section{REFERENCES}

1. Latifi $M$, Khatri $S$. Is spirometry necessary to diagnose and control asthma? Cleve Clin J Med 2017; 84: 597599.

2. Szefler SJ. Advances in pediatric asthma in 2013: coordinating asthma care. J Allergy Clin Immunol 2014; 133: 654-661.

3. Xue Z, Zhang $X, W u J, X u W C$, Li LQ, Liu F, Yu JE. Effect of treatment with geraniol on ovalbumin-induced allergic asthma in mice. Ann Allergy Asthma Immunol 2016; 116: 506-513.

4. $L i Q$, Gao $Y Z$, Li $Y L$, Jiang $L B$, Jiang $Y$. Imperatorin inhibits allergic airway inflammatory reaction and mucin secretion in ovalbumin-induced asthmatic rats. Trop $J$ Pharm Res 2016; 15: 2415-2420.

5. Zhang Q, Peng W, Wei SJ, Wei DN, Li RL, Liu J, Peng LY, Yang S, Gao YX, Wu CJ, Pu XF. Guizhi-ShaoyaoZhimu decoction possesses anti-arthritic effects on type II collagen-induced arthritis in rats via suppression of inflammatory reactions, inhibition of invasion \& migration and induction of apoptosis in synovial fibroblasts. Biomed Pharmacother 2019; 118: 109367
6. Zhang XG, Xue Z, Zhao YT, Bai L, Liu F, Li LQ, Wu J. Therapeutic effects of liver soothing pingchuan formula decoction on experimental asthma in $B A L B / c$ mice via regulation of nerve growth factor-tyrosine kinase $A$ pathway. Mol Med Rep 2018; 17: 6977-6984.

7. Zhao YT, Zhang $X$, Bai L. Effects of Chinese herbal medicine Pingchuan Formula on airway inflammation, interferon- $y$ and interleukin-4 in mice with asthma. J Chin Integr Med 2012; 10: 807-813.

8. Liu F, Yu J, Bai L. Role of Pingchuan Recipe on microRNA126 and GATA-3 expression in lung tissue of mice with asthma. Chin Trad Pat Med 2013; 35: 23242328.

9. International Journal for the Study of Animal Problems 1982 October-December; 3(4): 269

10. Lutz MB, Kukutsch N, Ogilvie AL, Robner S, Koch F, Romani N, Schuler G. An advanced culture method for generating large quantities of highly pure dendritic cells from mouse bone marrow. J Immunol Methods 1999; 223: 77-92.

11. Wu XY, Li J, Guo JZ. Ameliorative effects of curculigoside from Curculigo orchioides Gaertn on learning and memory in aged rats. Molecules 2012; 17 : 1010818.

12. Brüggemann TR, Fernandes $P$, Oliveira $L M$, Sato $M N$, Martins MA, Arantes-Costa FM. Cigarette smoke increases $C D 8 \alpha+$ dendritic cells in an ovalbumininduced airway inflammation. Front Immunol 2017; 8: 718.

13. Dai R, Liu J, Cai S, Zheng C, Zhou X. Delivery of adipose-derived mesenchymal stem cells attenuates airway responsiveness and inflammation in a mouse model of ovalbumin-induced asthma. Am J Transl Res 2017; 9: 2421-2428.

14. Conejero L, Khoulili S, Martínez-Cano S. Lung CD103+ dendritic cells restrain allergic airway inflammation through IL-12 production. JCI Insight 2017; 2: 90420.

15. Lajoie S, Lewkowich I, Suzuki Y. Complement-mediated regulation of the $I L-17 A$ axis is acentral genetic determinant of the severity of experimental allergic asthma. Nat Immunol 2010; 11: 928-935.

16. Tian $X$, Tian $X$, Huo $R$. Bacillus Calmette-Guerin alleviates airway inflammation and remodeling by preventing TGF- $\beta 1$ induced epithelial-mesenchymal transition. Hum Vaccin Immunother 2017; 13: 17581764.

17. Kim SH HJ, Lee YC. Ursolic acid, a potential PPARY agonist, suppresses ovalbumin-induced airway inflammation and Penh by down-regulating IL-5, IL-13, and $I L-17$ in a mouse model of allergic asthma. Eur $J$ Pharmacol 2013; 701: 131-143.

18. Bauerfeld C, Samavati L. Role of MEK1 in TLR4 Mediated Signaling. J Cell Signal 2017; 2:135.

19. Shalaby KH, Ai Heialy S, Tsuchiya K. The TLR4-TRIF pathway can protect against the development of experimental allergic asthma. Immunol 2017; 152: 138149.

Trop J Pharm Res, November 2021; 20(11): 2330 
20. Kim SH HJ, Lee JE, Lee YC. 18ß-Glycyrrhetinic acid, the major bioactive component of Glycyrrhizae Radix, attenuates airway inflammation by modulating Th2 cytokines, GATA-3, STAT6, and Foxp3 transcription factors in an asthmatic mouse model. Environ Toxicol Pharmacol 2017; 52: 99-113.

21. Sugimoto $A K R$, Mikami $N$. Transcription fFactors downstream of IL-4 and TGF- $\beta$ signals: analysis by quantitative PCR, western Blot, and flow cytometry. Methods Mol Biol 2017; 1585: 141-153.

22. Fontenot JD, Rudensky AY. Foxp3 programs the development and function of $C D+C D 25+$ regulatory $T$ cells. Nat Immunol 2003; 4: 330-336.
23. Miwa N, lilayakawa S, Miyazaki S. IDO expression on decidual and peripheral blood dendritic cells and monocytes/macrophages after treatment with CTLA-4 or interferon-gamma increase in normal pregnancy but decrease in spontaneous abortion. Mol Hum Reprod 2005; 11: 865-870.

24. Figueiredo $A B$, Souza-Testasicca M, Mineo TWP. Leishmania amazonensis-Induced CAMP triggered by adenosine $A 2 B$ receptor is important to inhibit dendritic cell activation and evade immune response in infected mice. Front Immunol. 2017; 8:849.

25. Chen YY, Bu H, Li YP. Surface phenotype on dendritic cells and their immunological significance. J Biomed Eng 1998; 15: 409-413. 